\title{
RESPONSIBLE RESEARCH AND INNOVATION - A CONCEPTUAL CONTRIBUTION TO THEORY AND PRACTICE OF TECHNOLOGY MANAGEMENT
}

\author{
Lukasz NAZARKO \\ Vilnius Gediminas Technical University, Vilnius, Lithuania \\ E-mail:l.nazarko@ieee.org
}

Received 16 April 2019; accepted 29 May 2019

\begin{abstract}
The concept of Responsible Research and Innovation (RRI) has become a popular term as a result of making it a cross-cutting theme for the Horizon 2020 Framework Programme of the European Union. RRI may be understood as a process by which societal actors and innovators become mutually responsive to each other with a view to the acceptability, sustainability and societal desirability of the innovation process and its products. The work presents a review of the state-of-art scientific literature on Responsible Research and Innovation (RRI) together with a synthesis of theoretical and practical challenges faced by this new concept. Mapping of RRI dimensions and its theoretical assumptions is performed. Bibliometric analysis of the scientific literature on RRI is carried out. The analysis of RRI-related projects is conducted. The attempt is made to clarify what RRI means for an enterprise in practical terms and what makes an innovation project in an enterprise a responsible one. Finally, a proposal for a closer interchange between RRI and Technology Assessment discourses is made together with an argument for a more extensive use of future-oriented methods that increase epistemic horizons of an innovating organisation.
\end{abstract}

Keywords: Responsible Research and Innovation (RRI), responsibility, European Union, innovation, technology management, technology assessment.

JEL Classification: O32, O33, O38.

\section{Introduction}

Responsible Research and Innovation (RRI) is a term that describes research and innovation (R\&I) activity that is ethically acceptable and socially desirable. The idea that technology is not value-neutral (van de Poel 2012) and that R\&I should be aligned with societal values, needs and concerns is decades old but the very term RRI has its origin only in 2009 when it appeared in the work by Robinson (2009) in the context of nanotechnology development. It was later adopted in the European Union as a new policy concept (European Commission 2011, European Parliament 2013). Then RRI has earned the status of a cross-cutting priority in EU's Horizon 2020 Framework Programme for Research and Innovation (H2020).

Von Schomberg (2012) proposes that RRI is understood as a transparent, interactive process by which societal actors and innovators become mutually responsive with a view to the (ethical) acceptability, sustainability and societal desirability of the innovation process and its marketable products (in order to allow a proper embedding of scientific and technological advances in our society).

According to the European Commission, the RRI concept has the following pillars (also called dimensions or policy agendas): 1) Ethics, 2) Gender Equality, 3) Governance, 4) Open Access, 5) Public Engagement, 6) Science Education. All actors engaged directly or indirectly in R\&I, i.e. researchers, policy makers, educators, business and industry innovators and civil society organisations, are expected to integrate RRI into their values, policies and actions in order to tackle the so-called Grand Societal Challenges. Particular process features are encouraged: 1) diversity and inclusion, 2) anticipation and reflection, 3) openness and transparency, 4) responsiveness and adaptive change (Owen et al. 2012). Comprehensive mind map

Copyright (C) 2019 The Authors. Published by VGTU Press.

This is an Open Access article distributed under the terms of the Creative Commons Attribution License (http://creativecommons.org/licenses/by/4.0/), which permits unrestricted use, distribution, and reproduction in any medium, provided the original author and source are credited.. 
encompassing and linking various dimensions RRI (grand challenges, policy agendas, resources, outcomes, engaged actors, related terms, process dimensions) is presented in Appendix 1.

The overview of available scientific literature and RRIrelated activities have allow the author to identify the following scientific problems: (1) Ontological and epistemological underpinnings and assumptions pertaining RRI have not been systematised, (2) Relevance of the concept to the practice of technology management in the market reality has not been sufficiently studied. In this paper, an attempt is made to increase the body of knowledge in the two above aspects. Author applies literature review, bibliometric analysis, mind mapping and logical construction methods to achieve the above stated goals.

\section{RRI - revisiting the notion of responsibility}

Even if RRI is not about prescribing what scientists and innovators should do, it is about making the entire world of science and innovation more responsible (...) write Kupper et al. (2015) in their report of the "RRI Tools" project. In relation to innovating enterprises, the communication from the same project assures readers that RRI is not about additional regulation but about making companies more profitable and socially responsible. Such statements about RRI make it evident that deconstructing the word "responsibility" is key to deeper analysis of this concept.

If responsibility were to by classified into legal responsibility, ethical (moral) responsibility and social responsibility (Gianni 2016), RRI is, for the most part, linked to the concept of ethical (moral) responsibility. However, paradoxically, the term "responsibility" is absent in the traditional ethical discourse where concepts like virtue, rights, contract, utility, or duty were prominent (Mitcham 2012). More precisely, responsibility may be understood as being accountable for one's action or as an act of attributing an action (and its results) to somebody. Pellé and Reber (2016) note that responsibility may have both positive and negative connotations; it may have both retrospective and prospective orientations (Figure 1).
There is a considerable number of issues related to RRI that pose difficulties and require further in-depth reflection. García et al. (2016) point at the following obstacles to good understanding and broad implementation of RRI:

- Lack of shared, consistent understanding of what it means to each of the actors' groups;

- Vagueness and very broad perspective that hampers the application of the concept in practical terms;

- Need to explain RRI in a different manner to different groups of actors and stakeholders;

- Absence of generally established norms;

- Scarcity of examples of good practice;

- Lack of understanding - especially in business context - of how and when implement it.

Furthermore, it is worth noting that the RRI pillars were named arbitrarily, probably as a result of internal bureaucratic processes in European Commission. No substantial justification for inclusion of those criteria has been offered. One may wonder why key issues such as sustainability, social justice or human rights are omitted. As Pellé and Reber (2016) mention, the pillars are not of the same order and some of them could be incorporated into each other. There is a level of redundancy, possible tensions and even contradictions among them.

\section{Bibliometric analysis of RRI}

Analysis of key bibliometric indicators sheds some light on the development process of RRI concept, most important contributors to the RRI discourse and the geographic dimension of that discourse. There have been up to date 360 documents registered in Scopus database (scientific articles, conference papers, book chapters, reviews, notes, editorials, books, letters) with the term "responsible research and innovation" included in the title, keywords or abstract. Significant rise in the popularity of the term may be observed since 2009, however year 2018 is the first one in eight years when the growing trend halted (Figure 2). In this light, it will be interesting to observe how the publication activity on RRI develops in the next years.

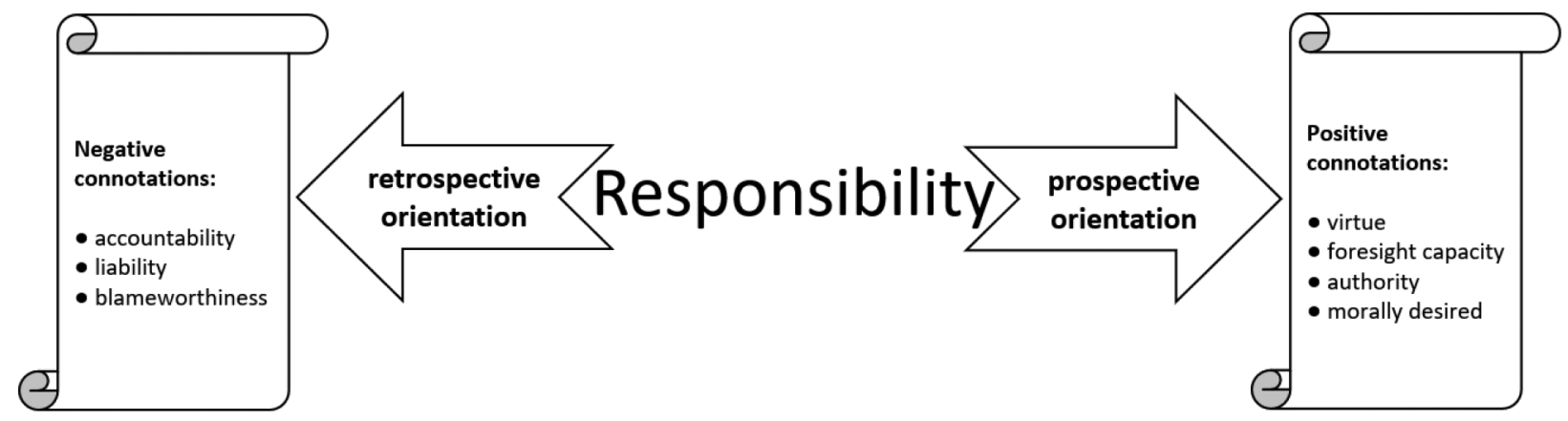

Figure 1. Retrospective and prospective orientation of responsibility (source: own elaboration based on Pellé and Reber 2016) 


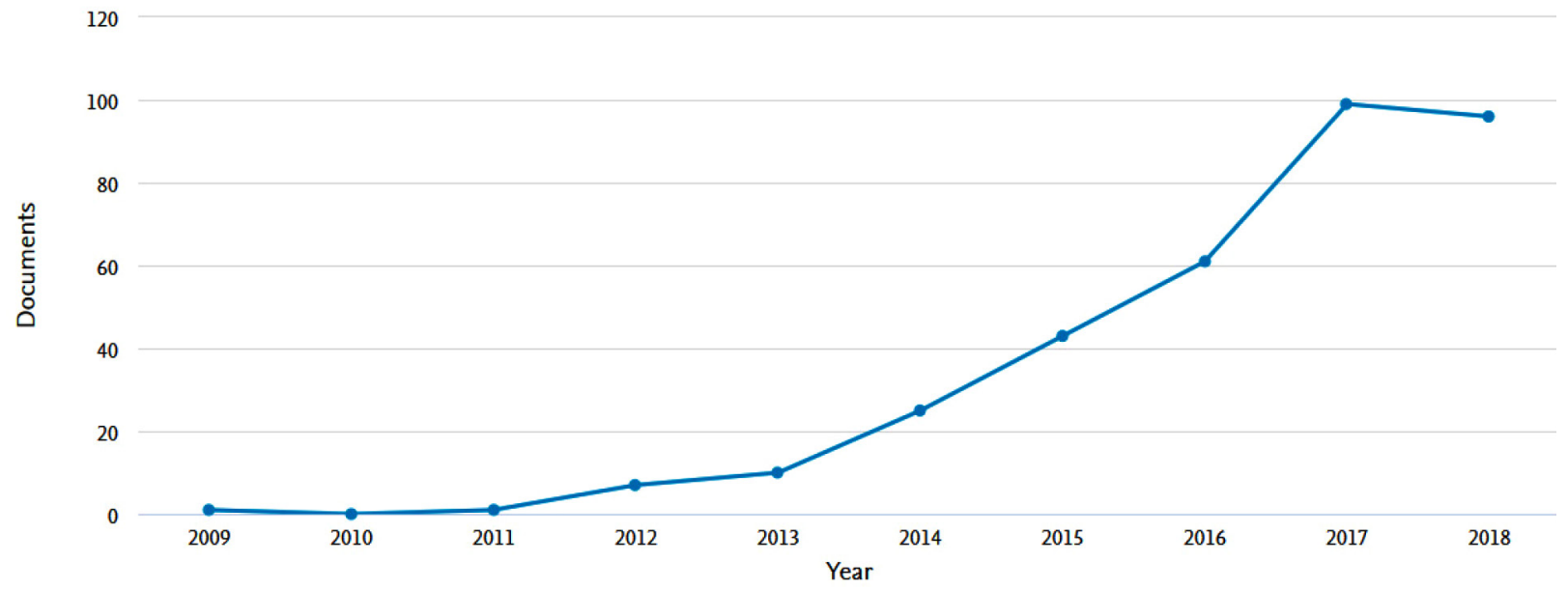

Figure 2. Number of publications on the topic of "responsible research and innovation" indexed in Scopus database (source: Scopus)

The RRI discourse is dominated by the European authors with United Kingdom, Netherlands and Germany occupying the first three places with the respect to the country of origin of the indexed documents. The first non-European country (United States) comes only in the 10th place. Especially symptomatic is the lack of Asian authors (who are increasingly prominent in terms of general scientific output) that deal with the topic. It may suggest that RRI is still a niche Europocentric concept that has not gained global recognition. 49 out of 360 indexed documents (ca. 14\%) report financial support from the European Union.

Citation data was extracted from the Scopus database (Figure 3). Works on RRI have been cited 2241 times since 2009. Two works take a clear lead: by Owen et al. 2012 (cited 346 times) and von Schomberg 2013 (cited 284 times). The graph shows a strong upward tendency in citing works related to RRI. This may be seen as an indicative of the importance of the topic as well as of the gradual accumulation of the body of knowledge on RRI.

In Figure 4 the most frequently used terms in relation to RRI are presented in clusters. The clusters reflect the cooccurrence of terms in the analysed publications but they don't form qualitatively coherent groups. Further analysis of the most frequent terms present in the literature on RRI resulted in the identification of the following aspects of RRI:

- Institutions (European Union)

- Actors (university, company, practitioner)

- Challenges (complexity, dilemma, legitimacy, technology development, transition, emergence)

- Sectoral relevance (synthetic biology, ICT)

- Desired features (anticipation, inclusion, responsiveness)

- Conceptual matters (definition, scope, framing)

Analysis of the occurrence frequency leads to some expected and unexpected conclusions. The expected conclusions are related to the institutional and conceptual matters as well as the desired features of RRI. They allow to infer that RRI is a European concept that still lacks the common understanding of its definition, scope and underlying assumptions. It is not surprising either that RRI aims both at universities and companies with the goal of making their research projects more anticipatory, inclusive and responsive to the needs, values and concerns of the society. What is surprising is the results of the analysis of the dominant thematic scope. Domination of synthetic biology and ICT over, for example, nanotechnology, health technologies, genetical engineering is not at all obvious.

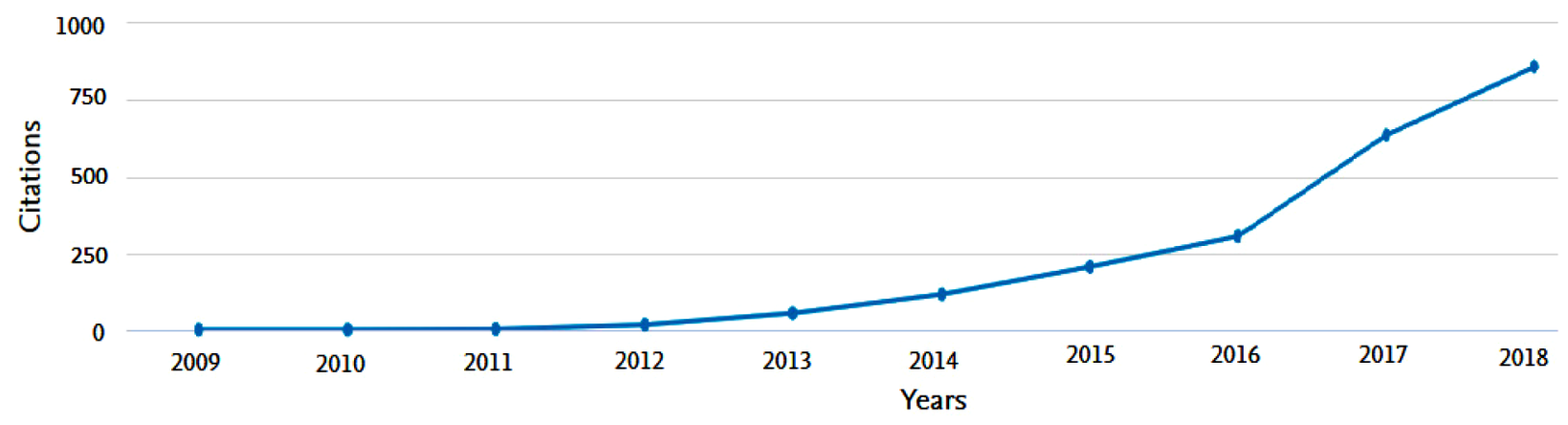

Figure 3. Citations of works on the topic of Responsible Research and Innovation indexed in Scopus database (source: Scopus) 


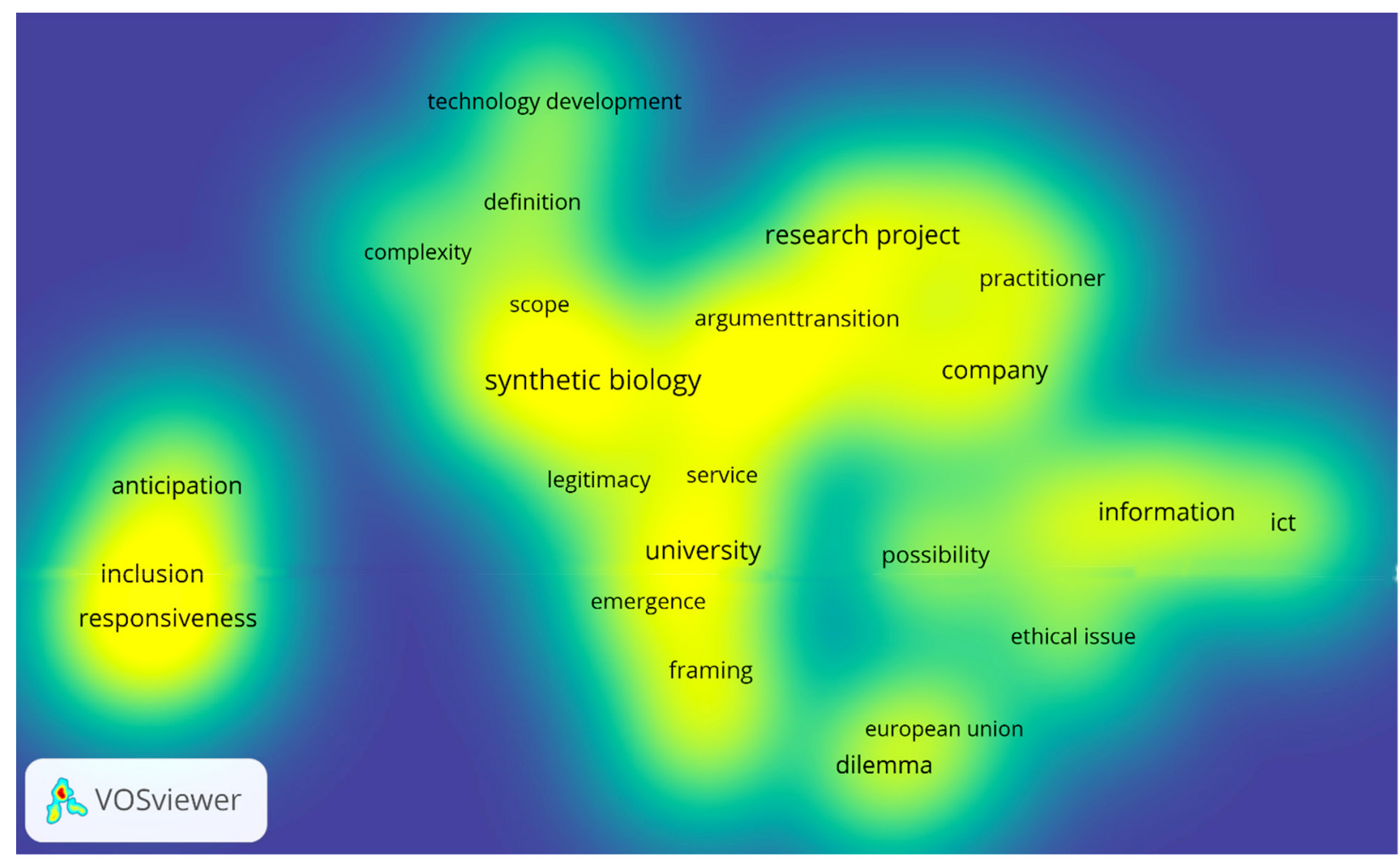

Figure 4. Clustering and density of key terms occurring in the literature on RRI on the basis of Scopus data (source: own elaboration with use of VOSviewer)

\section{Responsible Research and Innovation in the EU Programmes}

As indicated in the previous section, RRI is essentially a European concept promoted by the European Union. There have been at least 40 approved projects (with total funding of ca. $€ 105$ million) in the framework of Horizon 2020 Programme that deal with RRI from different perspectives and address different stakeholders. The exact number of RRI- related projects is difficult to determine since the aspects of responsibility feature in many initiatives sponsored under $\mathrm{H} 2020$, however in this paper only 40 projects directly relating to RRI are analysed. Most of them (34) may be found under the thematic priority of "Developing governance for the advancement of Responsible Research and Innovation". Remaining projects are funded under priorities "Integrate society in science and innovation" (four projects) and "Make scientific and technological careers attractive for young people" (two projects). Details of RRI-related topics addressed by the analysed projects are presented in Table 1 . They give a good overview of the directions and foci of the activities addressing RRI.

Table 1. Topic addressed by the RRI-related projects funded in the framework of Horizon 2020 Programme (source: own elaboration on the basis of Horizon Dashboard, https://webgate.ec.europa.eu/dashboard)

\begin{tabular}{|c|c|c|}
\hline Topic Description & $\begin{array}{c}\text { H2020 Signed } \\
\text { Grants }\end{array}$ & $\begin{array}{c}\text { H2020 EU } \\
\text { Contribution }\end{array}$ \\
\hline European Ethics and Research Integrity Network & 1 & $€ 1499000$ \\
\hline Fostering RRI uptake in current research and innovations systems & 2 & $€ 3089313$ \\
\hline Responsible Research and Innovation in industrial context & 3 & $€ 4723677$ \\
\hline Scientific Information in the Digital Age: Text and Data Mining (TDM) & 1 & $€ 1492370$ \\
\hline Innovative approach to release and disseminate research results and measure their impact & 1 & $€ 1951933$ \\
\hline Ethics in Research: Promoting Integrity & 1 & $€ 1987780$ \\
\hline Reducing the risk of exporting non ethical practices to third countries & 1 & $€ 2141173$ \\
\hline Science with and for Society National Contact Points (NCPs) in H2020 & 1 & $€ 1999594$ \\
\hline National Contact Points for quality standards and horizontal issues & 1 & $€ 1967828$ \\
\hline $\begin{array}{l}\text { Estimating the costs of research misconduct and the socio-economic benefit of research } \\
\text { integrity }\end{array}$ & 1 & $€ 999713$ \\
\hline
\end{tabular}


End of Table 1

\begin{tabular}{|c|c|c|}
\hline Topic Description & $\begin{array}{l}\text { H2020 Signed } \\
\text { Grants }\end{array}$ & $\begin{array}{l}\text { H2020 EU } \\
\text { Contribution }\end{array}$ \\
\hline Innovative methods for teaching ethics and research integrity & 2 & $€ 4994673$ \\
\hline Developing research integrity standard operating procedures & 1 & $€ 3999860$ \\
\hline Opening Research Organisations in the European Research Area & 2 & $€ 6405535$ \\
\hline New constellations of Changing Institutions and Actors & 2 & $€ 6947633$ \\
\hline Grounding RRI practices in research and innovation funding and performing organisations & 2 & $€ 2996434$ \\
\hline Engaging industry - Champions for RRI in Industrial Sectors & 1 & $€ 3549475$ \\
\hline Moving from constraints to openings, from red lines to new frames in Horizon 2020 & 1 & $€ 6799943$ \\
\hline Webs of Innovation Value Chains and Openings for RRI & 1 & $€ 2995565$ \\
\hline A Linked-up Global World of RRI & 1 & $€ 2999545$ \\
\hline Mapping the Ethics and Research Integrity Normative Framework & 1 & $€ 3770000$ \\
\hline The Ethics of informed consent in novel treatment including a gender perspective & 1 & $€ 3077198$ \\
\hline The Ethics of technologies with high socio-economic impact and Human Rights relevance & 1 & $€ 3996788$ \\
\hline $\begin{array}{l}\text { Promoting integrity in the use of research results in evidence based policy: a focus on non- } \\
\text { medical research }\end{array}$ & 1 & $€ 2800000$ \\
\hline $\begin{array}{l}\text { The ethical dimensions of IT technologies: a European perspective focusing on security and } \\
\text { human rights aspects }\end{array}$ & 2 & $€ 5663979$ \\
\hline RRI in support of sustainability and governance, taking account of the international context & 1 & $€ 3158613$ \\
\hline $\begin{array}{l}\text { Implementing a European Train-the-trainers initiative with regard to Ethics and Research } \\
\text { Integrity }\end{array}$ & 1 & $€ 2800000$ \\
\hline $\begin{array}{l}\text { Supporting structural change in research organisations to promote Responsible Research and } \\
\text { Innovation }\end{array}$ & 1 & $€ 3993633$ \\
\hline $\begin{array}{l}\text { Supporting structural change in research organisations to promote Responsible Research and } \\
\text { Innovation }\end{array}$ & 3 & $€ 9498335$ \\
\hline Responsible Research and Innovation in Higher Education Curricula & 2 & $€ 2998172$ \\
\hline TOTAL & 40 & $€ 105297756$ \\
\hline
\end{tabular}

Consortia formed to implement the RRI projects consisted of 475 participants from 48 countries (the same entity was counted multiple times if it participated in several consortia - some of them in as many as seven). There are only 27 participations (5,5\%) of entities from continents other than Europe: South Africa, China, Brazil, United States, India, Australia, Japan, Kenya, Chile, Colombia, Israel, Egypt, Jamaica. That fact provides another proof for the thesis about the Eurocentrism of the RRI concept. Three top countries in terms of number of participants and awarded funding are Germany, Netherlands and United Kingdom. Participants from these three countries constitute $29 \%$ of all participants of the RRI-related projects and consume $35 \%$ of the total funding (Figure 5).

RRI assumes engagement of all actors involved in research and innovation activities. The composition of participants of the RRI-related projects indicates that the interest in RRI is currently expressed mostly by higher education institutions (200 participations) and public research organisations (105 participations). Engagement of enterprises in the RRI project consortia is far below the level that would reflect business' role in R\&I processes. There are 60 participations of the for-profit organisation in the RRI projects, including 48 small and medium enterprises (Figure 6).

The conducted analysis reveals that RRI adoption is concerns mostly public entities (universities, research institutions and funding agencies) in Western Europe. For-profit organisations constitute merely $13 \%$ of all participations in RRI-related projects. There are few cross-continental partnerships in the implementation of the projects. This has to change since R\&I activity is increasingly global in its nature. RRI cannot become a globally recognised concept if only Western European actors are involved in shaping and promoting it (van de Poel et al. 2017).

\section{RRI and Technology Management (rationale, requirements, benefits)}

RRI is sometimes considered to be a proposition that applies more to publicly funded research institutions rather than to market driven technology management processes and corporate research and innovation (Ceicyte and Petraite 2018). The challenge of getting industry on board 
of the RRI discourse has been recognised in the academia and in the EU policy community. Various resources and initiatives have been addressing this issue (Iatridis and Schroeder 2016, Martinuzzi et al. 2012, Scholten and Blok 2015, Stahl 2018). One of the reports lists the potential benefits of adopting RRI (Responsible Industry 2017):

- enhancing company's reputation,

- decreasing business risk and unintended consequences,

- strengthening public trust in the safety of products,
- adopting an environmentally friendly profile,

- increasing company's competitiveness.

It is noticeable that very similar set of arguments is used to encourage business towards more corporate social responsibility (Nazarko 2019). It must be admitted that there is little or no evidence that following RRI principles increases company's competitiveness and profitability in the long run. The promise of increased profits from RRI should rather be seen as an ideal model in which more responsibility is translated into more robust strategic choices,

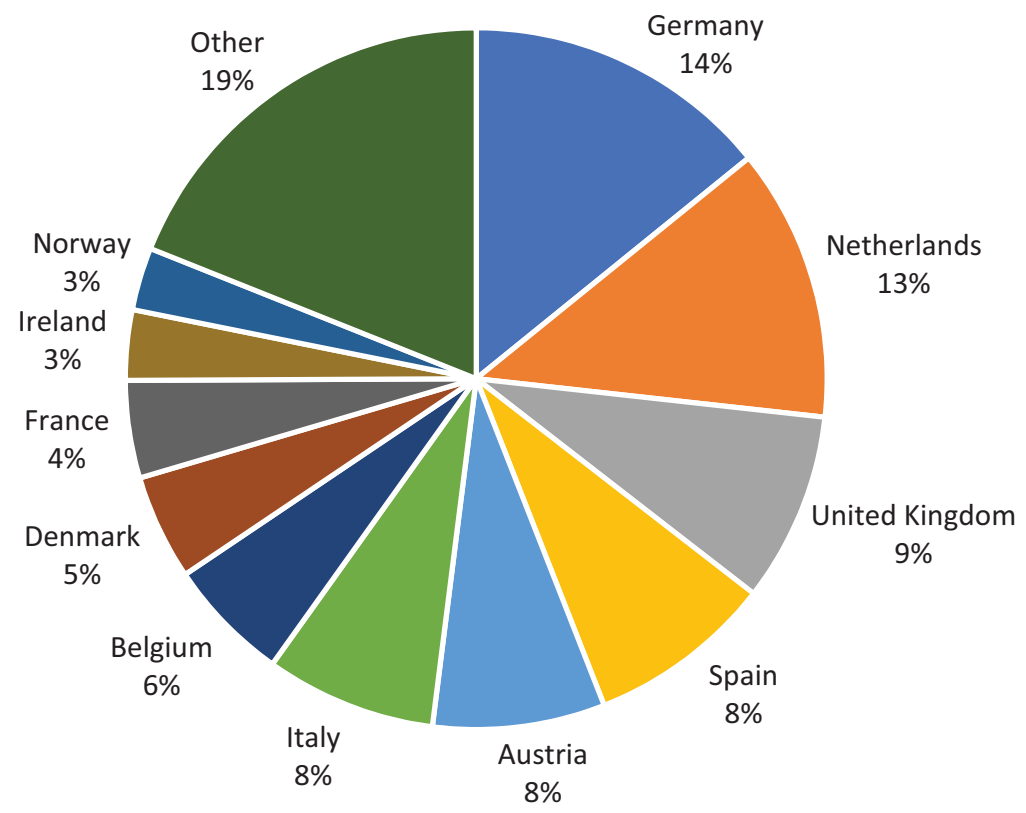

Figure 5. Funding of the RRI-related project participants by country (source: own elaboration on the basis of Horizon Dashboard, https://webgate.ec.europa.eu/dashboard)

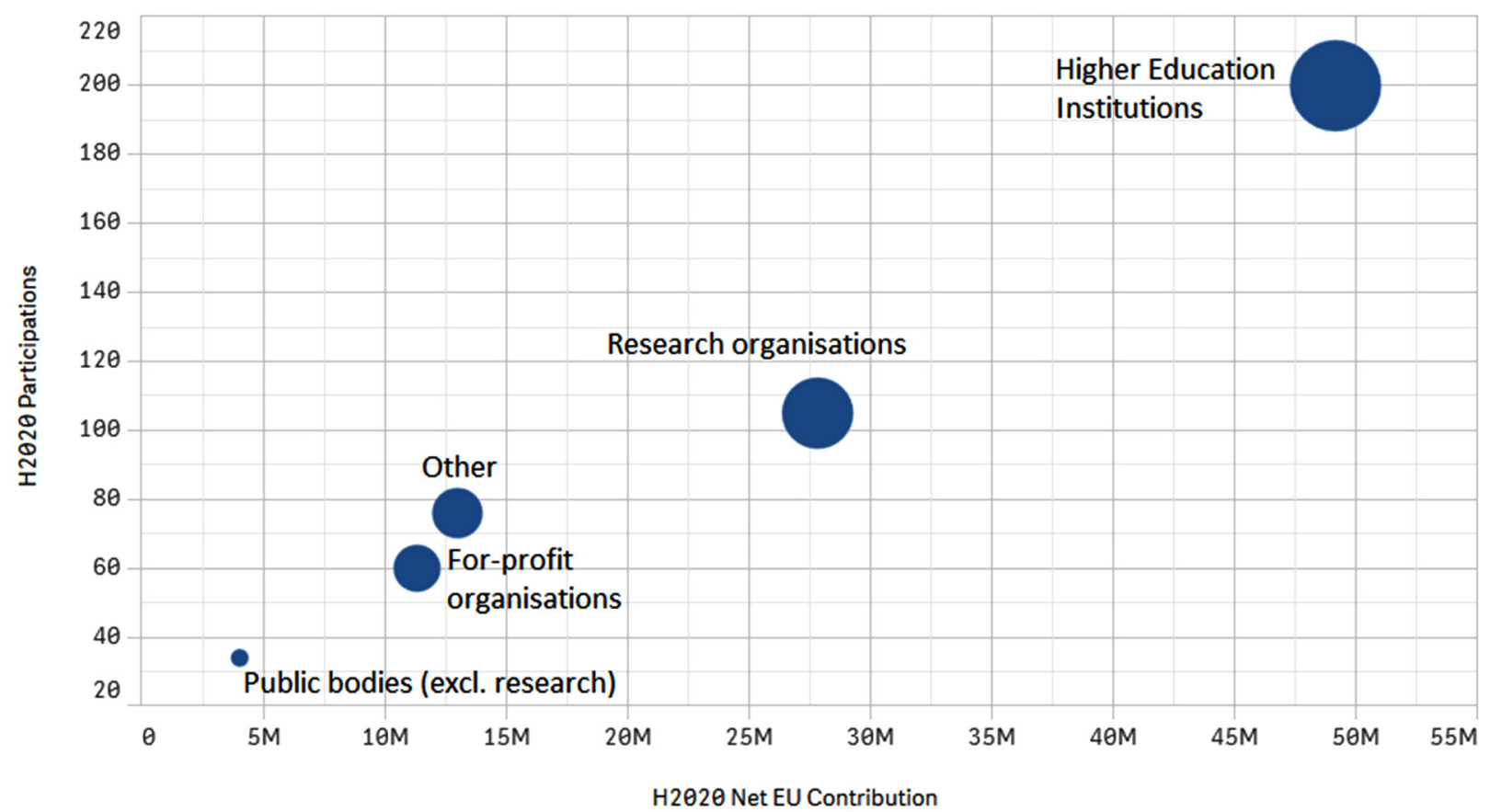

Figure 6. RRI-related project participants by type (source: Horizon Dashboard, https://webgate.ec.europa.eu/dashboard) 


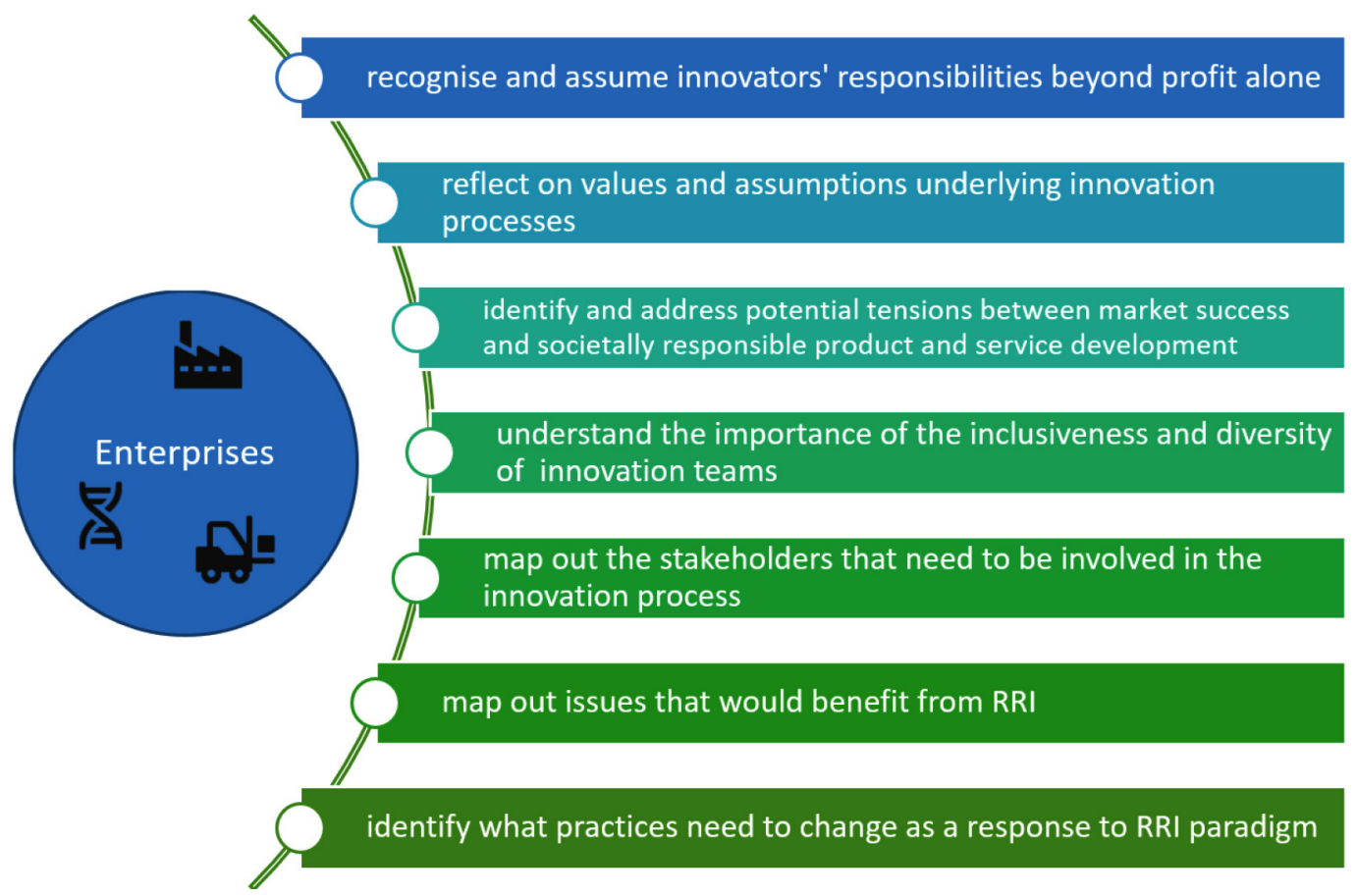

Figure 7. Competences, skills and actions needed in industry to foster the RRI agenda (source: own elaboration on the basis of Smallman et al. 2016)

increased productivity (Chodakowska and Nazarko 2017) and "future-proof" product portfolios.

Smallman et al. (2016) try to give a practical answer to the question "What to do if you want your business to follow RRI principles?” (Figure 7).

Following the line of thought of Ceicyte and Petraite (2018) it is argued in this paper that decomposing RRI into Responsible Research (relating more to the publicly funded scientific endeavours) and Responsible Innovation (more relevant to industrial context) may bring more clarity to the reflection on responsibility in $R \& I$. The proposed distinction helps understand better how the notion of responsibility may be measured in both public and private (corporate) context.

Only few metrics and indicators of responsibility (Ravn et al. 2015) are relevant to businesses - the ones that relate to market and marketing, social and environmental impact of products, company's stakeholders or technology management. The metrics found in the literature clearly focus on policy-makers and public research performing and funding organizations. Study by Flipse and Yaghmaei (2018) confirms that there is a clear need to develop frameworks and key performance indicators that would connect better to the $R \& I$ activities in industry.

\section{Conclusions}

Mitcham (2012) suggests that the development of the notion of responsibility and its application of in legal, religious, engineering, scientific, and philosophical contexts is inherently connected with the technological progress of humanity. RRI, and its rapid evolution, may be therefore seen as an expected (and needed) consequence of the advancement and the growing complexity of the technosocial systems. Despite its dilemmas and inconsistencies, RRI offers potential to integrate the concepts of technology management, Technology Assessment and engineering ethics. In this respect, Technology Assessment may serve an anchor concept (Grunwald 2009, Grunwald 2011, Grunwald 2014, Nazarko 2016).

Reflections on responsibility in technology management have revealed an important difficulty for entities involved in RRI, namely: a particular action can be seen and assessed differently before (ex ante) and after (ex post) it is taken. In consequence, it is often impossible to reliably state if a certain ReI activity is responsible or not. Partial remedy to that challenge consists in the recommendation to make an extensive use of future-oriented methods and techniques that increase one's epistemic horizons and systematise the knowledge of what is possible, plausible and/or probable (Ejdys et al. 2015, Halicka 2016, Radziszewski et al. 2016, Nazarko 2017).

Ultimately, one may conclude that the full realisation of RRI principles and priorities can only be possible iffundamental changes are introduced not only in the R\&I activities of different actors but also in the way the contemporary economic system assigns value to products and services.

\section{Funding}

This work was supported by the European Social Fund under the No 09.3.3-LMT-K-712 "Development of 
Competences of Scientists, other Researchers and Students through Practical Research Activities" measure.

\section{References}

Ceicyte J, Petraite M (2018) Networked responsibility approach for responsible innovation: perspective of the firm. Sustainability 10 (6): 1720. https://doi.org/10.3390/su10061720

Chodakowska E, Nazarko J (2017) Environmental DEA method for assessing productivity of European countries. Technological and Economic Development of Economy 23 (4): 589-607. https://doi.org/10.3846/20294913.2016.1272069

Ejdys J, Ustinovičius L, Stankevičienė J (2015) Innovative application of contemporary management methods in a knowledge-based economy - interdisciplinarity in science. Journal of Business Economics and Management 16 (1): 261-274. https://doi.org/10.3846/16111699.2014.986192

European Parliament (2013) Regulation (EU) No 1291/2013 of the European Parliament and of the Council of 11 December 2013 establishing Horizon 2020 - the Framework Programme for Research and Innovation (2014-2020) and re-pealing Decision No 1982/2006/EC.

European Commission (2011) DG Research Workshop on Responsible Research \& Innovation in Europe, Brussels, 16-17 May 2011.

Flipse SM, Yaghmaei E (2018) The Value of "Measuring” RRI Performance in Industry. In: Ferri et al., Governance and Sustainability of Responsible Research and Innovation Processes. Cham: Springer, 41-47. https://doi.org/10.1007/9783-319-73105-6_6

García D, Zuazua E, Perat B (2016) The RRI Toolkit. RRI Tools project https://www.rri-tools.eu/documents/10184/107098/ RRITools_D3.2-TheRRIToolkit.pdf

Gianni R (2016) Responsibility and freedom: the ethical realm of RRI, London: ISTE. https://doi.org/10.1002/9781119277354

Grunwald A (2009) Technology assessment: Concepts and methods. In: Meijers A (Ed) Philosophy of technology and engineering sciences vol. 9. Amsterdam: Elsevier, 1103-1146.

Grunwald A (2011) Responsible innovation: bringing together technology assessment, applied ethics, and STS research. Enterprise and Work Innovation Studies 7: 9-31.

Grunwald A (2014) Technology assessment for responsible innovation. In: van den Hoven J, Doorn N, Swierstra T, Koops BJ, Romijn H (Eds) Responsible Innovation 1: Innovative Solutions for Global Issues. Cham: Springer, 15-32. https://doi.org/10.1007/978-94-017-8956-1_2

Halicka K (2016) Innovative classification of methods of the Future-oriented Technology Analysis. Technological and Economic Development of Economy 22 (4): 574-597. https://doi.org/10.3846/20294913.2016.1197164

Horizon Dashboard (2018) https://webgate.ec.europa.eu/dashboard

Iatridis K, Schroeder D (2016) Responsible research and innovation in industry: the case for corporate responsibility tools. Cham: Springer. https://doi.org/10.1007/978-3-319-21693-5

Kupper F, Klaassen P, Rijnen M, Vermeulen S, Woertman R, Broerse J (2015) A catalogue of good RRI practices. RRI Tools project https://www.rri-tools.eu/documents/10184/107098/ RRITools_D1.4-CatalogueOfGoodRRIPractices.pdf

Martinuzzi A, Blok V, Brem A, Stahl B, Schönherr N (2018) Responsible research and innovation in industry - challenges, insights and perspectives. Sustainability 10 (3): 702. https:// doi.org/10.3390/su10030702

Mitcham C (2012) Technology and the burden of responsibility. In: Values and Ethics for the 21st Century. BBVA, 141-164.

Nazarko L (2016) Responsible research and innovation - a new paradigm of technology management. 9th International Scientific Conference "Business and Management 2016", 12-13 May 2016, Vilnius, Lithuania. http://doi.org/10.3846/ bm. 2016.71

Nazarko L (2017) Future-oriented technology assessment. Procedia Engineering 182: 504-509. http://doi.org/10.1016/j.proeng.2017.03.144

Nazarko L (2019) Responsible research and innovation in industry: from ethical acceptability to social desirability. In: Golinska P, Spychala M (Eds) Corporate social responsibility in the manufacturing and services sectors. Springer: Berlin-Heidelberg, 127-138. https://doi.org/10.1007/978-3-642-33851-9_7

Owen R, Macnaghten Ph, Stigloe J (2012) Responsible research and innovation: From science in society to science for society, with society. Science and Public Policy 39: 751-760. https://doi. org/10.1093/scipol/scs093

Pellé S, Reber B (2016) From ethical review to responsible research and innovation. London: ISTE.

Radziszewski P, Nazarko J, Vilutiene T, Debkowska K, Ejdys J, Gudanowska A, Halicka K, Kilon J, Kononiuk A, Kowalski KJ, Krol JB, Nazarko L, Sarnowski M (2016) Future trends in road pavement technologies development in the context of environmental protection. The Baltic Journal of Road and Bridge Engineering 11 (2): 160-168. https://doi.org/10.3846/bjrbe.2016.19

Ravn T, Nielsen MW, Mejlgaard N (2015) Metrics and indicators of responsible research and innovation, monitoring the evolution and benefits of responsible research and innovation (MoRRI) https://www.rri-tools.eu/documents/10184/47609/MORRI-D3.2/

Responsible Industry (2017) Guide for the implementation of Responsible Research and Innovation (RRI) in the industrial context (2017) http://www.responsible-industry.eu/dissemination/deliverables/R-I_02_Guide.pdf

Robinson DKR (2009) Co-evolutionary scenarios: An application to prospecting futures of the responsible development of nanotechnology. Technological Forecasting and Social Change 76 (9): 1222-1239. https://doi.org/10.1016/j.techfore.2009.07.015

Scholten VE, Blok V (2015) Foreword: Responsible innovation in the private sector. Journal on Chain and Network Science 15 (2): 101-105. https://doi.org/10.3920/JCNS2015.x006

Smallman M, Bouwers M, Miller S (2016) Learning Outcomes. RRI Tools project https://www.rri-tools.eu/documents/10184/193151/RRIToolsTraining-LearningOutcomes. pdf

Stahl B (2018) RRI in Industry: On the Translation of the RRI Discourse into the Private Domain. Orbit Journal 1 (3).

van de Poel I (2012) The relation between forward-looking and backward looking responsibility. In: Vincent N, Van de Poel I, Van de Hoven J (Eds) Moral Responsibility, Beyond 
Free Will \& Determinism. Dordrecht: Springer. https://doi. org/10.1007/978-94-007-1878-4_3

van de Poel I, Asveld L, Flipse S, Klaassen P, Scholten V, Yaghmaei E (2017) Company Strategies for Responsible Research and Innovation (RRI): A Conceptual Model. Sustainability 9 (11): 2045. https://doi.org/10.3390/su9112045

von Schomberg R (2012) Prospects for technology assessment in a framework of responsible research and innovation. In:
Dusseldorp M, Beecroft R (Eds) Technikfolgen abschätzen lehren. Wiesbaden: VS Verlag für Sozialwissenschaften, 39-61. https://doi.org/10.1007/978-3-531-93468-6_2

von Schomberg R (2013) A vision of responsible research and innovation. In: Owen R, Bessant J, Heintz M (Eds). Responsible Innovation: Managing the Responsible Emergence of Science and Innovation in Society, Chichester: John Wiley \& Sons, 51-74. 


\section{APPENDIX 1. RESPONSIBLE RESEARCH AND INNOVATION MIND MAP}

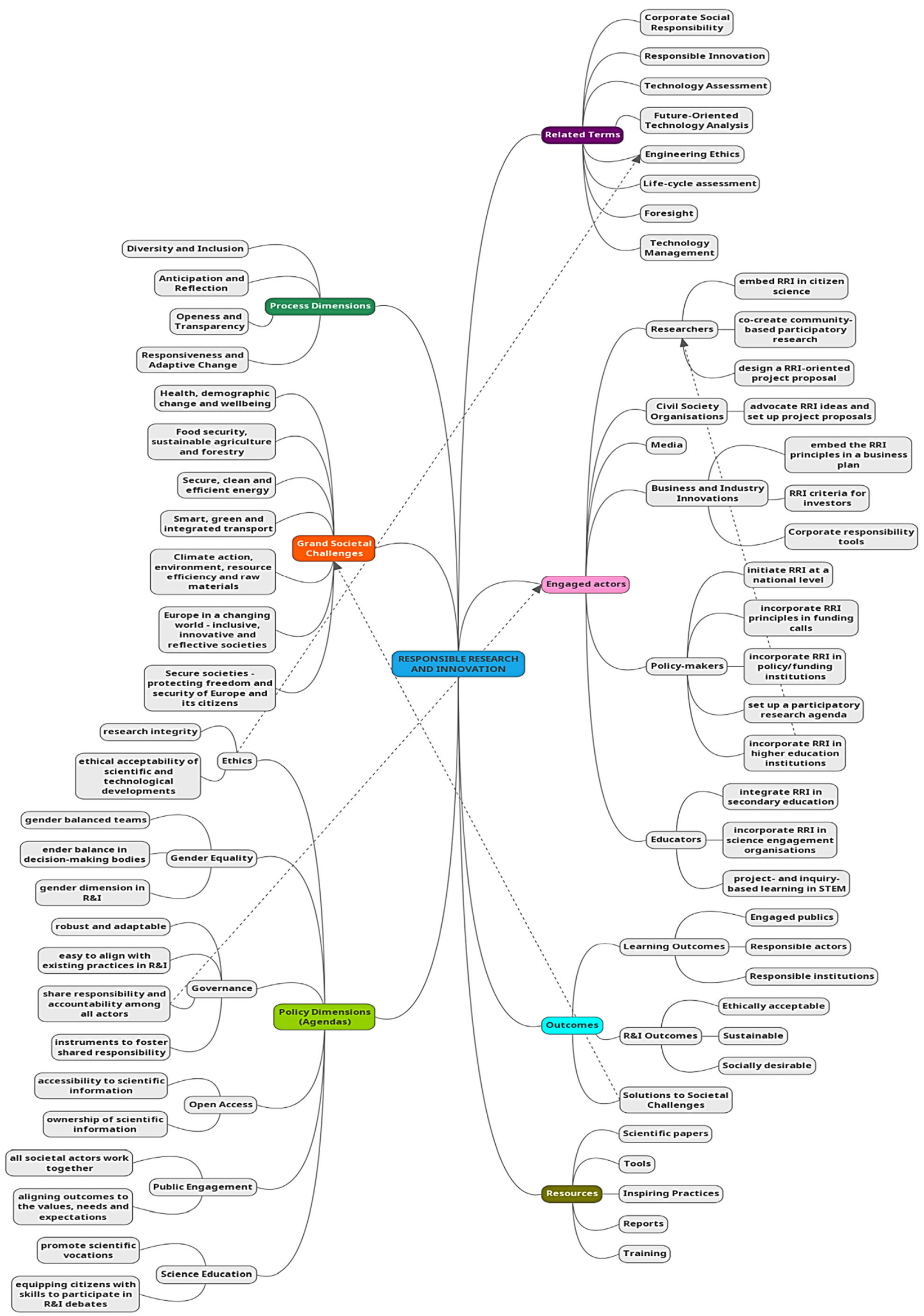

